\title{
Formulation and In-Vitro Evaluation of Darifenacin Hydrobromide as Buccal Films
}

\section{Ishraq K. Abbas*, ${ }^{*}$, Nawal A. Rajab ${ }^{* *}$ and Ahmed A. Hussein ${ }^{* * *}$}

* Faculty of Pharmacy, Al-Rafidain University College, Baghdad, Iraq. *Department of Pharmaceutics, College of Pharmacy, University of Baghdad, Baghdad, Iraq.

\section{Abstract}

Overactive bladder $(\mathrm{OAB})$ affects about $16 \%$ of the adults and rises with increasing age. OAB lead to various symptoms such as urgency, incontinence, urinary frequency and nocturia. Darifenacin hydrobromide (DH) is the more recent uroselective M3 receptor antagonist for treating uncomplicated OAB.

Fast dissolving buccal films are the most innovative oral solid dosage form because of their flexibility and comfort. This study aims to formulate DH as fast dissolving buccal films (FDBFs) using a solvent casting method to increase its bioavailability by reducing the effect of first pass metabolism in the liver.

Films were prepared by using polyvinyl alcohol as a film forming polymer, glycerol and tween 80 . Different types and concentrations of superdisintegrants (croscarmellose sodium, sodium starch glycolate, indion 414) were used to select the best formula by studying the physicochemical properties of the films, disintegration time (DT) and percent drug release.

The results revealed that formula (F9) that containing $7.5 \mathrm{mg} \mathrm{DH}, 2 \% \mathrm{w} / \mathrm{v}$ PVA, $30 \% \mathrm{w} / \mathrm{w}$ glycerol, $0.5 \% \mathrm{w} / \mathrm{v}$ tween $80,4 \% \mathrm{w} / \mathrm{w}$ indion 414 was the preferred formula. F9 showed the shortest in-vitro disintegration time (31.28sec). In-vitro dissolution profile showed the lowest $\mathrm{T}_{80 \%}$ of the drug in $3.05 \mathrm{~min}$ and the highest release of the drug $(94 \%)$ within $5 \min \left(\mathrm{D}_{5 \min } \%\right)$.

It was concluded that the FDBFs of DH could be considered as a promising drug delivery system with an enhanced disintegration and dissolution rate and better patient compliance.

Keywords: Darifenacin hydrobromide, Overactive bladder, Fast dissolving buccal films.

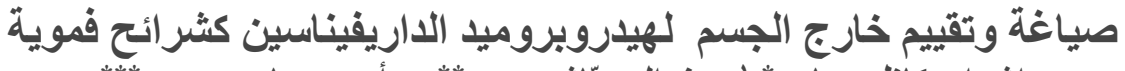

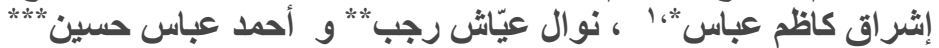

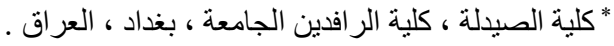

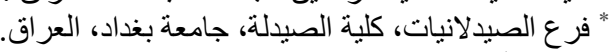

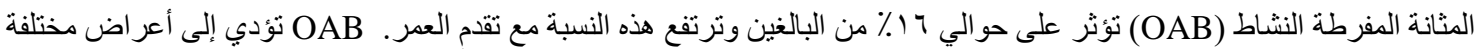

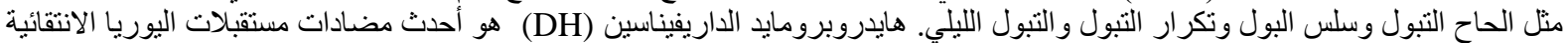

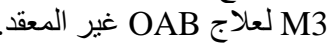

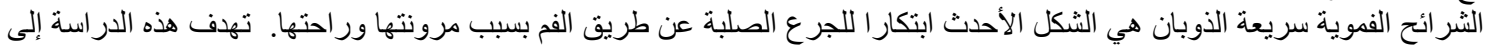

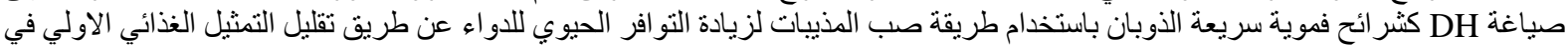

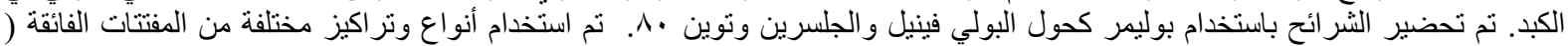

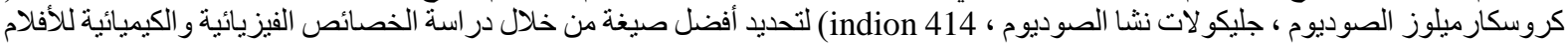

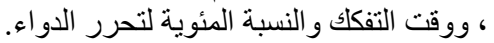

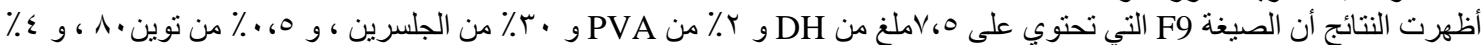

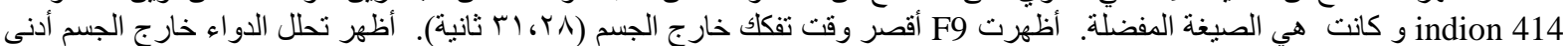

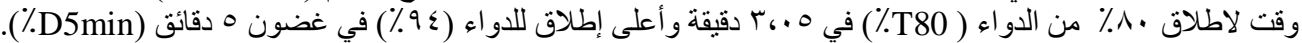

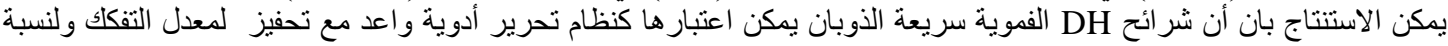

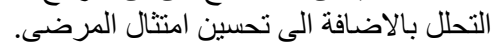

\section{Introduction}

In the past few decades, development and imagination have ended up basic competence for making progress in the development of novel dosage forms. But, every dosage form has shown some drawbacks like pain of the parenteral dosage form and chocking of tablets and capsules ${ }^{(1)}$.

The oral solid dosage forms are characterized by ease of administration and exact dosing, but it is sometimes problematic because of decline in bioavailability, long onset time of action and swallowing difficulty especially for pediatric and geriatric ${ }^{(2)}$.Most of pharmaceutical manufacturers have focused in their researches on developing new dosage form to achieve patient convenience. Among many drug delivery systems, the fast dissolving films are incredibly prominent among pediatrics and

${ }^{1}$ Corresponding author E-mail:ishraqalmualla@yahoo.com

Received: 15/ 5 /2019

Accepted: 17/7 /2019

Iraqi Journal of Pharmaceutical Sciences 
geriatrics and have started gaining big popularity for their rapid disintegration or dissolution, selfadministration even without water or chewing (3). The oral cavity is a preferred site for drug administration because of easily drug application by patient and avoidance of possible drug degradation in the GIT in addition to bypassing first-pass hepatic metabolism ${ }^{(1)}$. Oral mucosa is the lining of the oral cavity. The membrane of mucosa cells is hydrophobic in nature and might be selective for hydrophobic molecules only, while the hydrophilic molecules pass the oral mucosal membrane through the para-cellular pathway since the cytoplasm and intercellular spaces are hydrophilic in nature. After absorption, the drug is transported through facial vein, which then drains into general circulation, bypassing the liver, therefore warn off drug from first pass metabolism ${ }^{(4)}$.

Overactive bladder $(\mathrm{OAB})$ is a common and distressing disorder characterized by incontinence, urinary frequency and nocturia. The symptoms of $\mathrm{OAB}$ have been attributed to involuntary contractions of the bladder muscle. This supports the rationale for using a drug that antagonizes the M3mediated parasympathetic excitation of the detrusor smooth muscle contraction ${ }^{(5)}$.

Darifenacin hydrobromide (DH) is the first M3-selective receptor antagonist. It has a higher selectivity for muscarinic receptors of the bladder. It was approved by FDA to be used for the symptomatic treatment of OAB in $2004^{(6)}$. DH molecular weight is $507.472 \mathrm{~g} / \mathrm{mol}$. It is slightly soluble in water $(6.03 \mathrm{mg} / \mathrm{ml})$. Its melting point is $228-236{ }^{0} \mathrm{C}^{(7)}$. It is subjected to extensive first-pass metabolism after oral administration. The absolute bioavailability of $\mathrm{DH}$ from $7.5 \mathrm{mg}$ and $15 \mathrm{mg}$ prolonged release tablet was estimated to be $15.4 \%$ and $18.6 \%$ respectively ${ }^{(8)}$. This study is aimed to prepare DH as fast dissolving buccal films (FDBFs) to enhance patient's compliance.

\section{Materials and methods}

\section{Materials}

DH supplied by Hyperchemical comp., China. Polyvinyl alcohol (AVONCHEM, UK), glycerol (Fluka Chemi AG, Switzerland), tween 80 (SD Fine-Chem. Limited, Mumbai, India), croscarmellose sodium and sodium starch glycolate (Hyperchemical comp. China), indion 414 (Ion Exchange India Ltd, Mumbai).

\section{Methods}

Preparation method of darifenacin hydrobromide fast dissolving buccal films

Solvent casting technique was used in the preparation of DH FDBFs by using $9 \mathrm{~cm}$ diameter petri dishes. $2 \% \mathrm{w} / \mathrm{v}$ of PVA solution was prepared by dissolving the polymer in deionized water with constant stirring $(120 \mathrm{rpm})$ by magnetic stirrer to form a homogenous polymeric solution. To this polymer solution, excipients were added separately. DH was dissolved, in $30 \mathrm{ml}$ absolute ethanol at 60
${ }^{0} \mathrm{C}$ with stirring to form a clear solution. Then the two mediums were mixed together using magnetic stirrer. The mixture $(63 \mathrm{ml})$ was set aside to ensure air bubbles removal, then casted in a petri dish $(9 \mathrm{~cm}$ diameter) and kept in an oven at $50^{\circ} \mathrm{C}$ overnight. The dried film was then removed and cut into $(2 \mathrm{~cm} \times 2 \mathrm{~cm})$ films ${ }^{(9)}$.

Nine formulas (F1-F9) were prepared using different superdisintegrants types \{croscarmellose sodium (CCS), sodium starch glycolate (SSG) and indion 414$\}$ and concentrations $(2 \%, 3 \%$ and $4 \%)$ to select the best formula (Table 1).

Evaluation of darifenacin hydrobromide fast dissolving buccal films:

Physical appearance of the prepared films

Physical appearance was evaluated by visual inspection for homogenisity, clearness and surface texture.

\section{Weight variation}

It was done by weighing ten films individually, and average weights were calculated. The accepted film weight should not significantly deviate from weight average ${ }^{(10)}$.

\section{Thickness of the films}

It was measured by using a standard Vernier caliper. Six films were measured at five positions, and average thickness was calculated ${ }^{(11)}$.

\section{Drug content uniformity}

Three films were placed in $100 \mathrm{ml}$ phosphate buffer (pH6.8) solutions individually and kept on a magnetic stirrer for $30 \mathrm{~min}$. The solution was filtered by filter syringe $(0.45 \mu \mathrm{m})$, and $\mathrm{DH}$ amount was measured spectrophotometrically ${ }^{(12)}$.

\section{Folding endurance (FE)}

FE was determined by manual repeated folding of film at specified site until it breaks or cracks, and average values were calculated and reported. FE of more than 300 gives a good idea about the flexibility and toughness of the formulation ${ }^{(11)}$.

\section{In-vitro disintegration time (DT)}

It was measured visually by using a petri dish method. The test was done by taking three films of each patch in a petri dish ( $5 \mathrm{~cm}$ diameter) separately, and after adding $2 \mathrm{ml}$ of deionized water for each film, the petri dish was shaken smoothly and continuously, then measure the time at which the FDBFs start to break down or disintegrate ${ }^{(11)}$.

\section{Determination of surface $\mathrm{pH}$}

This is essential to investigate the opportunity of side effects when using the films invivo, because sharp acidic or basic $\mathrm{pH}$ may irritate the mucosal membrane of the oral cavity. To measure the $\mathrm{pH}$ value; three films were allowed to dissolve in $2 \mathrm{ml}$ of deionized water separately, and the $\mathrm{pH}$ of the obtained solution is determined using pH-meter ${ }^{(11)}$. 
Table 1. Composition of darifenacin hydrobromide fast dissolving buccal films $\left(4 \mathrm{~cm}^{2}\right)$

\begin{tabular}{|c|c|c|c|c|c|c|c|c|c|c|c|c|c|c|c|c|c|c|}
\hline \multirow{2}{*}{$\begin{array}{c}\stackrel{\dot{\Xi}}{\Xi} \\
\stackrel{\sigma}{\Xi} \\
\stackrel{\Xi}{\Xi} \\
\stackrel{\Xi}{0}\end{array}$} & \multirow{2}{*}{\multicolumn{2}{|c|}{ 疍 }} & \multirow{2}{*}{ 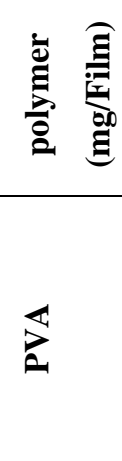 } & \multirow{2}{*}{ 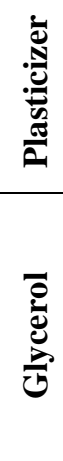 } & \multirow{2}{*}{ 罣 } & \multirow{2}{*}{ 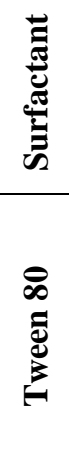 } & \multirow{2}{*}{ 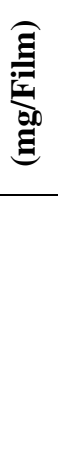 } & \multirow{2}{*}{ 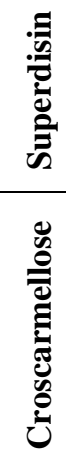 } & \multirow{2}{*}{ 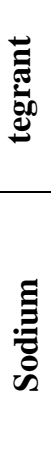 } & \multicolumn{3}{|l|}{ 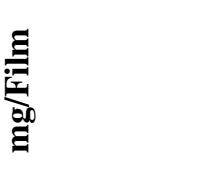 } & \multirow{2}{*}{ 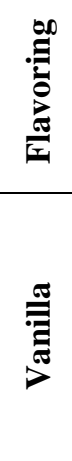 } & \multirow{2}{*}{\multicolumn{2}{|c|}{ 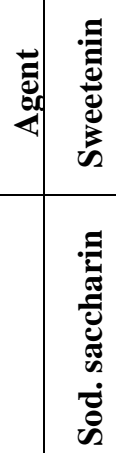 }} & \multirow{2}{*}{$\begin{array}{l}\overrightarrow{0} \\
\text { ơd } \\
\text { ond } \\
\text { on } \\
\end{array}$} & \multirow{2}{*}{ 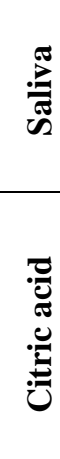 } & 晜 \\
\hline & & & & & & & & & & 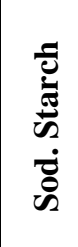 & $\frac{\stackrel{\Xi}{\pi}}{8}$ & 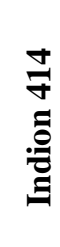 & & & & & & \\
\hline F 1 & 7.5 & & 41 & 12 & & 10 & & 1.6 & & & & & 2.5 & & 2.5 & & 2.5 & \\
\hline F 2 & 7.5 & & 41 & 12 & & 10 & & 2.3 & & & & & 2.5 & & 2.5 & & 2.5 & \\
\hline F 3 & 7.5 & & 41 & 12 & & 10 & & 3.1 & & & & & 2.5 & & 2.5 & & 2.5 & \\
\hline F 4 & 7.5 & & 41 & 12 & & 10 & & & & 1.6 & & & 2.5 & & 2.5 & & 2.5 & \\
\hline F 5 & 7.5 & & 41 & 12 & & 10 & & & & 2.3 & & & 2.5 & & 2.5 & & 2.5 & \\
\hline F 6 & 7.5 & & 41 & 12 & & 10 & & & & \begin{tabular}{|l|}
3.1 \\
\end{tabular} & & & 2.5 & & 2.5 & & 2.5 & \\
\hline F 7 & 7.5 & & 41 & 12 & & 10 & & & & & & $\begin{array}{l}1 . \\
6\end{array}$ & 2.5 & & 2.5 & & 2.5 & \\
\hline F 8 & 7.5 & & 41 & 12 & & 10 & & & & & & $\begin{array}{l}2 . \\
3\end{array}$ & 2.5 & & 2.5 & & 2.5 & \\
\hline F 9 & 7.5 & & 41 & 12 & & 10 & & & & & & $\begin{array}{l}3 . \\
1\end{array}$ & 2.5 & & 2.5 & & 2.5 & \\
\hline
\end{tabular}

\section{In-vitro dissolution stud}

It was done by using USP type II (paddle apparatus) with $300 \mathrm{ml}$ of Phosphate buffer ( $\mathrm{pH}$ 6.8). The medium was adjusted to rotate at $50 \mathrm{rpm}$, and the temperature was maintained at $37 \pm 0.5^{\circ} \mathrm{C} .5$ $\mathrm{ml}$ Samples were taken by using a syringe at regular intervals $(1,2,3,4,5,10,15$ and 20min) replaced with $5 \mathrm{ml}$ buffer medium to maintain sink condition. Then before analyzing the withdrawn samples using $\mathrm{UV}$-spectrophotometry at $\mathrm{DH} \lambda \max$, they were filtered by filter syringe $(0.45 \mu \mathrm{m})$. Then the dissolution profile of the drug is constructed by plotting the percent of accumulative drug release against the time ${ }^{(13)}$.

$\mathrm{T}_{80 \%}(\mathrm{~min})$ which is the time needed to release $80 \%$ of the drug and $\mathrm{D}_{5 \min }(\%)$ which represent the percentage of drug released in 5 min was used to study the effect of different factors on the dissolution profile ${ }^{(14)}$.

Effect of superdisintegrant type and concentration

Three formulas (F1, F2 and F3) were developed to illustrate CCS effect at different concentrations $(2 \%, 3 \%$ and $4 \% \mathrm{w} / \mathrm{w}$ of total dry constituents of the film) on the mechanical, physical properties and dissolution profile of DH films. SSG with $2 \%, 3 \%$ and $4 \%$ concentrations used to study its effect on F4, F5 and F6. The last superdisintegrant used was indion 414 , also with same concentrations in F7, F8 and F9.

\section{Characterization of selected formula:}

Percentage moisture loss (PML)

This was done to determine physical stability of films. It was detected by putting three accurately weighed films in a desiccator that containing silica gel beads. After 72 hours; films were taken and weighed again ${ }^{(9)}$.

PML $=$ (Initial weight-Final weight)*100/Initial weight

\section{Percentage moisture absorption (PMA)}

PMA was used to check the physical stability of films at high humid condition. It was identified by keeping three accurately weighed films in a desiccator containing a saturated solution of calcium chloride, at $25^{\circ} \mathrm{C}$ for 72 hours, then after three days, films were reweighed.

PML $=$ (Final weight-Initial weight $)^{*} 100 /$ Initial weight.

\section{Evaluation of mechanical property of the films: Tensile strength (TS)}

It is maximum force required for breakdown of the film. The film were cut around a standard $9 \times 2$ $\mathrm{cm}^{2}$ template (dumbbell) and put between two clamps of tensometer and pulled at a rate of 5 $\mathrm{mm} / \mathrm{min}$. TS was measured by mega Pascal (MPa) ${ }^{(9)}$. Tensile strength $=$ Load at break $(\mathrm{N}) * 100 /$ Width $\times$ Thickness $\left(\mathrm{mm}^{2}\right)$. 


\section{Percent of elongation (\%E)}

$\% \mathrm{E}$ is the stretching and distortion of the film when a force is applied on it ${ }^{(11)}$.

$\% \mathrm{E}=$ Final length-initial length*100/Initial length

Young's modulus (YM)

It is defined as the measure of the stiffness of film. So rigid and fragile films exhibit high TS and YM with small $\% \mathrm{E}^{(11)}$.

YM= Slop*100/ Strip thickness $\times$ Cross-head speed. Drug-polymer compatibility study

It was examined by Fourier Transform Infrared Spectroscopy (FTIR), Differential Scanning Calorimetric Studies (DSC) and X-Ray Powder Diffraction (XRPD).

Fourier transform infrared spectroscopy

FTIR confirmed the compatibility of the drug and the formulation. Spectra of pure drug and formulations were determined by potassium bromide $(\mathrm{KBr})$ disc method. The spectrum was recorded for the drug, polymer, 1:1 physical mixture of polymer and drug and the selected formula. Samples and $\mathrm{KBr}$ were mixed and pressed in the form of a disc, then it was analyzed by FTIR spectroscopy from $4000-400 \mathrm{~cm}^{-1(9)}$.

Differential Scanning Calorimetric Studies (DSC)

DSC scans were done for the drug, polymer, 1:1 physical mixture of drug and polymer and for the selected film. A certain amount of the sample was introduced in a typical aluminum pans and increasing the temperature at a constant rate $\left(10^{\circ} \mathrm{C} / \mathrm{min}\right)$, at a temperature range of $8^{\circ} \mathrm{C}$ up to 300 ${ }^{\circ} \mathrm{C}^{(9)}$.

$X$-Ray powder diffraction (XRPD)

XRPD study can be used to confirm the crystalline nature of materials. The diffractograms of $\mathrm{DH}$, polymer and the selected formula were studied. The study was approved by using Shimadzu XRD-6000 powder XRPD at continuous scan range of $5^{\circ}-60^{\circ}$ of $2 \Theta$. The operating voltage was $40(\mathrm{kV})$ and current $30 \mathrm{~mA}^{(11)}$.

Stability studies

Stability study was performed by storing the selected DH formula films in an aluminum foil in sealed container and placed them in three ovens that maintained at three temperatures of $40^{\circ} \mathrm{C}, 50^{\circ} \mathrm{C}$, and $60^{\circ} \mathrm{C}$ for three months. Then the films were withdrawn every 14 days and examined them for physical, mechanical properties and drug content ${ }^{(9)}$. Statistical analysis

The results were demonstrated as a mean of triplicate models \pm standard deviation (SD) and were tested by the one-way analysis of variance(ANOVA) to determine if the changes in the applied factors are statistically significant $(\mathrm{P} \leq 0.05)$ or non-significant $(\mathrm{P}>0.05)$.

\section{Results and Discussion}

Evaluation of darifenacin hydrobromide fast dissolving Buccal Films

Physical appearance

All prepared films showed colorless, translucent, and homogenous smooth surface properties.

\section{Weight variation}

The average weights were between $0.08 \pm 0.007$ to $0.102 \pm 0.01$ (Table2). Weight variations was due to variation in excipients concentration of each formula while low SD from the mean demonstrates that films were uniform.

\section{Thickness of the films}

The average thickness was between $0.164 \pm 0.02$ to $0.21 \pm 0.02 \mathrm{~mm}$ (Table2). A very low SD indicates that the method used for the formulation was applicable.

\section{Drug content uniformity}

The formulated $\mathrm{DH}$ films showed a drug content ranged from $90.8 \% \pm 2$ to $102 \% \pm 0.35$ (Table2). The accepted range of content uniformity labeled in the United States Pharmacopeia (USP) is varied from $90 \%$ to $110 \%{ }^{(25)}$. On this basis, it was concluded that DH was distributed uniformly throughout the films.

\section{Folding endurance (FE)}

All formulations resisted cracking for more than 300 folding times (Table2). This result is consistent with research was done by Londhe and Umalkar in $2012^{(15)}$.

\section{In-vitro disintegration time}

DT was studied in triplicate, and results were ranged between 31.28 $\pm 1.45-44.97 \pm 3$ secs (Table2). Determination of surface $\mathrm{pH}$

Measurement of prepared films showed an acceptable surface $\mathrm{pH}$ value $(4.1 \pm 0.06-5.1 \pm 0.28)$ (Table2). Since films surface $\mathrm{pH}$ did not deviate sharply from the neutral $\mathrm{pH}$, there will not be any irritation to the mucosal lining of the oral cavity. 
Table 2. Physical evaluation parameters of darifenacin hydrobromide fast dissolving buccal films $\left(4 \mathrm{~cm}^{2}\right)$.

\begin{tabular}{||l|l|l|l|l|l|l||}
\hline $\begin{array}{l}\text { F } \\
\text { No. }\end{array}$ & $\begin{array}{l}\text { Weight } \\
\text { Variation } \\
\mathbf{n = 1 0}\end{array}$ & $\begin{array}{l}\text { Thickness } \\
\mathbf{( m m} \\
\mathbf{n = 6}\end{array}$ & $\begin{array}{l}\text { Drug content } \\
\mathbf{( \% )} \\
\mathbf{n = 3}\end{array}$ & $\begin{array}{l}\text { Folding } \\
\text { Endurance } \\
\mathbf{n}=\mathbf{3}\end{array}$ & $\begin{array}{l}\text { In vitro } \\
\mathbf{D T}(\mathbf{s e c}) \\
\mathbf{n}=\mathbf{3}\end{array}$ & $\begin{array}{l}\text { Surface } \\
\mathbf{p H} \\
\mathbf{n}=\mathbf{3}\end{array}$ \\
\hline F 1 & $0.08 \pm 0.007$ & $0.18 \pm 0.009$ & $99 \pm 0.007$ & $>300$ & $39.3 \pm 0.95$ & $4.4 \pm 0.06$ \\
\hline F 2 & $0.09 \pm 0.09$ & $0.19 \pm 0.01$ & $98.1 \pm 0.04$ & $>300$ & $37.3 \pm 2.5$ & $4.2 \pm 0.06$ \\
\hline F 3 & $0.102 \pm 0.01$ & $0.21 \pm 0.02$ & $90.8 \pm 2$ & $>300$ & $35.73 \pm 0.8$ & $4.1 \pm 0.06$ \\
\hline F 4 & $0.095 \pm 0.03$ & $0.164 \pm 0.02$ & $97.44 \pm 0.04$ & $>300$ & $44.97 \pm 3$ & $4.2 \pm 0.15$ \\
\hline F 5 & $0.1 \pm 0.01$ & $0.175 \pm 0.02$ & $102 \pm 0.35$ & $>300$ & $43.33 \pm 3$ & $4.5 \pm 0.0$ \\
\hline F 6 & $0.17 \pm 0.01$ & $0.195 \pm 0.02$ & $96.9 \pm 1$ & $>300$ & $40.59 \pm 4.35$ & $4.1 \pm 0.2$ \\
\hline F 7 & $0.09 \pm 0.008$ & $0.17 \pm 0.01$ & $95.36 \pm 0.04$ & $>300$ & $38.88 \pm 3.2$ & $5.1 \pm 0.28$ \\
\hline F 8 & $0.095 \pm 0.01$ & $0.18 \pm 0.02$ & $98.1 \pm 2$ & $>300$ & $37.33 \pm 1.15$ & $4.8 \pm 0.0$ \\
\hline F 9 & $0.097 \pm 0.01$ & $0.195 \pm 0.01$ & $99 \pm 0.1$ & $>300$ & $31.28 \pm 1.44$ & $4.9 \pm 0.05$ \\
\hline
\end{tabular}

\section{Mean \pm SD}

\section{Effect of superdisintegrant}

Superdisintegrants, are poor water solubility substances with functional hydration capacity that can facilitate disintegration with a smaller quantity of them either by swelling action, capillary (wicking) action or combination of both mechanisms ${ }^{(16)}$.

\section{Effect of superdisintegrant concentration}

All formulas (F1-F9) had acceptable mechanical properties with $\mathrm{FE}>300$ as seen in table 2. Films of F1, F2 and F3 were prepared with $2 \%$, $3 \%$ and $4 \% \mathrm{w} / \mathrm{w}$ of CCS respectively to study its effect on In-vitro DT and release profile of the prepared films.

Table 3 and figure1 showed that films DT declined from $39.31 \mathrm{sec}$ to $37.3 \mathrm{sec}$, and $35.73 \mathrm{sec}$ with increasing in CCS concentration from $2 \%$ to $3 \%$, and to $4 \%$, with a significant variation $(\mathrm{p}<0.05)$ between F1-F3, while there is no significance ( $p>0.05$ ) between F1-F2 and F2-F3.

There was significant changes $(\mathrm{p}<0.05)$ in the dissolution profiles between $\mathrm{F} 1$ and $\mathrm{F} 3$ in $\mathrm{T}_{80 \%}$ and $\mathrm{D}_{5 \min }(\%)$ that was $(8.9 \mathrm{~min}$ and $65 \%)$ for $\mathrm{F} 1$ and (4.3 min and $87.5 \%$ ) for $\mathrm{F} 3$, whereas the difference was non-significant ( $p>0.05$ ) between $\mathrm{F} 1$ and $\mathrm{F} 2$. There were also significant changes $(p<0.05)$ between F2 and F3 (Table4 and Figure2). Similar results noticed by by $\mathrm{Xu}$ et al. ${ }^{(17)}$.

These results may be related to CCS wicking effect that provide pathways in the film just like capillaries in which liquid is drawn up and rupture the inter-particulate bonds causing the film to break apart ${ }^{(18)}$. Gissinger and Stamm ${ }^{(19)}$ reported that the disintegration and dissolution could not be only explained by the formation of the porous capillary network and other factors like swelling force are also essential for disintegration especially for CCS.
Films of F4, F5 and F6 were prepared with 2\%, 3\% and $4 \%$ of SSG. DT measurement revealed that F6 had lowest time (40.97sec) (Table3 and Figure1), but with no significance between the three formulas $(p>0.05)$. Decrease in DT by using 4\% SSG was observed by Sharma that prepared salbutamol sulfate fast disintegrating tablet with different concentration of SSG; $1 \%, 2 \%, 4 \%, 6 \%, 8 \%$ and $10 \%$ where the lowest disintegration time was by using $4 \%$ of SSG $^{(20)}$.

Table3 and figure2 showed that lowest $\mathrm{T}_{80 \%}$ time and $\mathrm{D}_{5 \min } \%$ (4.31min, 85.6\%) was in F6 with a non-significant difference ( $\mathrm{p}>0.05)$ when compared with $(8.63 \mathrm{~min}, 53.57 \%)$ and $(7.05 \mathrm{~min}, 60.87 \%)$ of F4 and F5 respectively. These results correspond to research findings of Haque and Sheela ${ }^{(21)}$.

SSG effects may be due to swelling property of SSG that involves rapid absorption of water leading to an enormous increase in films volume that overcomes interconnection bond of other ingredients resulting in fast disintegration and fast release of drug ${ }^{(21)}$.

Last type used was indion in $2 \%, 3 \%$ and $4 \%$ w/w concentrations of F7, F8 and F9 respectively. Concerning DT; F9 showed $31.28 \mathrm{sec}$ with significant variation $(\mathrm{p}<0.05)$ when compared with F8 and F7 (37.33sec and 38.88sec) respectively (Table 3 and Figure1).

Indion effects (Table4 and Figure2) reveals that $\mathrm{F} 9$ showed $3.05 \mathrm{~min} \mathrm{~T}_{80 \%}$ and $94 \% \mathrm{D}_{5 \min } \%$ with significant difference $(\mathrm{p}<0.05)$ of both parameters when compared with F8 (5.3min, 77.8\%) and F7 (7.4min, 68.71\%). Chandira et al., (2008) showed similar results ${ }^{(22)}$.

These effects could be due to indion ability to swell upon contact with water without lump formation and without adhesive tendency that causes uniform film disintegration and then dissolution $^{(18,23)}$. 
In this study, by using range of $2 \%$ to $4 \%$ of Superdisintegrants, it was clear that the more concentrated superdisintegrant, the lower In-vitro DT, the shorter $\mathrm{T}_{80 \%}$ and the higher $\mathrm{D}_{5 \min }$ for all types of Superdisintegrants.

\section{Effect of superdisintegrant type}

All Superdisintegrants used had a positive effect on DT and increasing the release of the drug from the formulas in a shorter time, but it was clear that indion was the best one followed by CCS then
SSG with significant difference $(\mathrm{p}<0.05)$ (Tables 3,4 and Figures 1,2). This may be related to prompt swelling tendency of indion on wetting, thus causing rapid disintegration ${ }^{(23)}$.

Amin et al., formulated roxithromycin, dicyclomine hydrochloride and montelukast with four superdisintegrants (indion, CCS, SSG and crospovidone), the optimized formulas were containing indion for all drugs. These results reconcile with current research ${ }^{(23)}$.

Table 3. Disintegration time of darifenacin hydrobromide fast dissolving buccal films .

\begin{tabular}{|c|c|c|c|}
\hline \multirow{2}{*}{$\begin{array}{l}\text { F no. } \\
\mathrm{N}=3\end{array}$} & \multicolumn{3}{|c|}{ (95\% Confidence Interval for Mean } \\
\hline & DT (sec) Mean \pm Std. Error & Std. Deviation & Std. Error \\
\hline F1 (2\%CCS) & $39.31 \pm 0.55$ & 0.95 & 0.55 \\
\hline $\mathrm{F} 2(3 \% \mathrm{CCS})$ & $37.30 \pm 1.47$ & 2.56 & 1.47 \\
\hline F3 (4\%CCS) & $35.73 \pm 0.45$ & 0.77 & 0.44 \\
\hline F4 (2\%SSG) & $44.97 \pm 1.73$ & 3.00 & 1.7 \\
\hline F5 (3\%SSG) & $43.33 \pm 1.76$ & 3.05 & 1.76 \\
\hline F6 (4\%SSG) & $40.59 \pm 2.5$ & 4.35 & 2.51 \\
\hline F7 (2\%indion) & $38.88 \pm 1.84$ & 3.20 & 1.84 \\
\hline F8 (3\%indion) & $37.33 \pm 0.66$ & 1.15 & 0.66 \\
\hline F9 (4\% indion) & $31.28 \pm 0.83$ & 1.44 & 0.83 \\
\hline
\end{tabular}

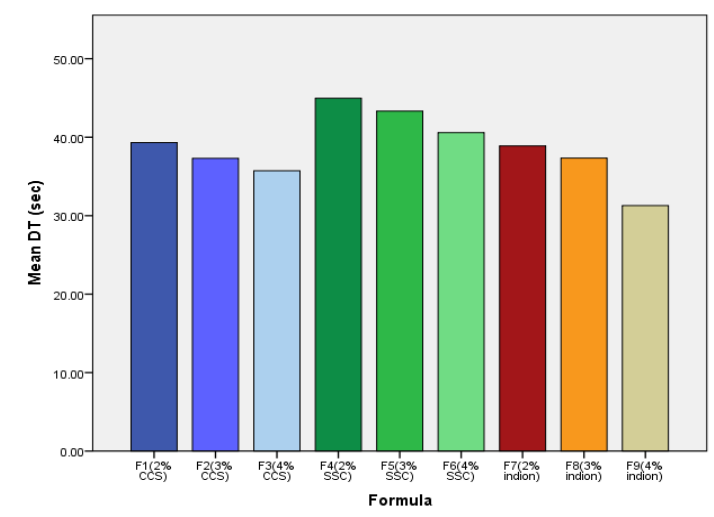

Figure 1. Disintegration time of darifenacin hydrobromide fast dissolving buccal films.

Table 4. Dissolution parameters of darifenacin hydrobromide fast dissolving buccal films

\begin{tabular}{||l|l|l||}
\hline Formula no. & $\mathbf{D}_{\mathbf{5 m i n}}(\boldsymbol{\%})$ & $\mathbf{T}_{\mathbf{8 0} \%}(\mathbf{m i n})$ \\
\hline F1 (2\%CCS) & 65 & 8.9 \\
\hline F2 (3\%CCS) & 70.27 & 6.95 \\
\hline F3 (4\%CCS) & 87.5 & 4.13 \\
\hline F20 2\%SSG & 53.57 & 8.63 \\
\hline F21 3\%SSG & 60.87 & 7.05 \\
\hline F22 4\%SSG & 85.6 & 4.31 \\
\hline F23 2\%Indion & 68.71 & 7.4 \\
\hline F24 3\%Indion & 77.8 & 5.30 \\
\hline F25 4\%Indion & 94 & 3.05 \\
\hline
\end{tabular}

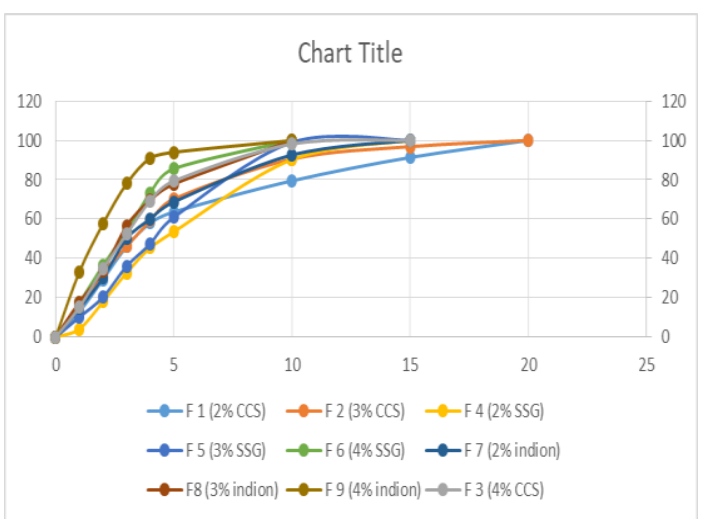

Figure 2. Dissolution profile of darifenacin hydrobromide fast dissolving buccal films

\section{Characterization of selected formula}

F9 that composed of $2 \%$ w/v PVA, $30 \%$ w/w glycerol and $4 \% \mathrm{w} / \mathrm{w}$ of indion showed shortest DT of $31.28 \mathrm{sec}$ and superior dissolution profile with $\mathrm{T}_{80 \%}$ time of $3.05 \mathrm{~min}$ and $\mathrm{D}_{5 \mathrm{~min}}$ of $94 \%$ was selected as the best formula.

\section{Percent moisture loss (PML)}

F9 showed PML of $6.41 \pm 0.9 \%$. The obtained value was close to that reported by Jasim in $2006^{(24)}$. Percent moisture absorb (PMA)

F9 PMA was $3.5 \pm 0.7$ which was very close to the PMA for PVA films investigated by Tamer in $2018^{(11)}$.

\section{Evaluation of mechanical property of the films}

Mechanical property can be expected by studying some parameters like FE, TS, \%E and YM. FE results were mentioned previously and listed in table 2. 


\section{Tensile strength}

TS of F9 was $2.089 \pm 0.7 \mathrm{MPa}$. It was close to results of Tamer $(2.78 \mathrm{MPa})^{(11)}$.

\section{Percent elongation}

$\mathrm{E} \%$ value was $62 \pm 2.1 \%$ for the $\mathrm{F} 9$ which is near to that obtained by Noor ${ }^{(9)}$.

\section{Young's modulus}

YM was $8.74 \pm 0.4 \mathrm{MPa}$ for F9. It is clear from all mechanical properties that the selected film is of excellent flexibility and this corresponds to findings of Arora and Chakraborty (2017) in their review on PVA films ${ }^{(25)}$.

\section{Drug-polymer compatibility Test}

There are some parameters that reflect the drug-polymer compatibility like:

\section{Fourier transform infra-red (FTIR)}

The FTIR spectrum of the DH, PVA polymer, 1:1 physical mixture (DH and PVA) and
F9 are shown in figures 3, 4, 5, and 6 respectively. The main characteristic peaks of $\mathrm{DH}$ at wave numbers (in $\mathrm{cm}^{-1}$ ) are: 3464 for $\mathrm{N}-\mathrm{H}$ asymmetric stretching of amide (3500-3400), 3251 and 3205 for $\mathrm{N}-\mathrm{H}$ symmetric stretching of amide (3300-3180), 1662 for $\mathrm{C}=\mathrm{O}$ stretching of amide (1695-1630), 1350 for $\mathrm{C}-\mathrm{N}$ stretching of tertiary amine (13601310), 1215 for C-O stretching of furan (13001000)..

From FTIR results, it was observed that there was no chemical interaction as well as no changes in the peaks of fingerprint region obtained in $\mathrm{DH}$ spectrum to that of physical mixture spectra.

All functional groups in DH spectrum were maintained in the spectrum of F9. The results indicate that no chemical interaction occurred between $\mathrm{DH}$ and excipients used in F9.

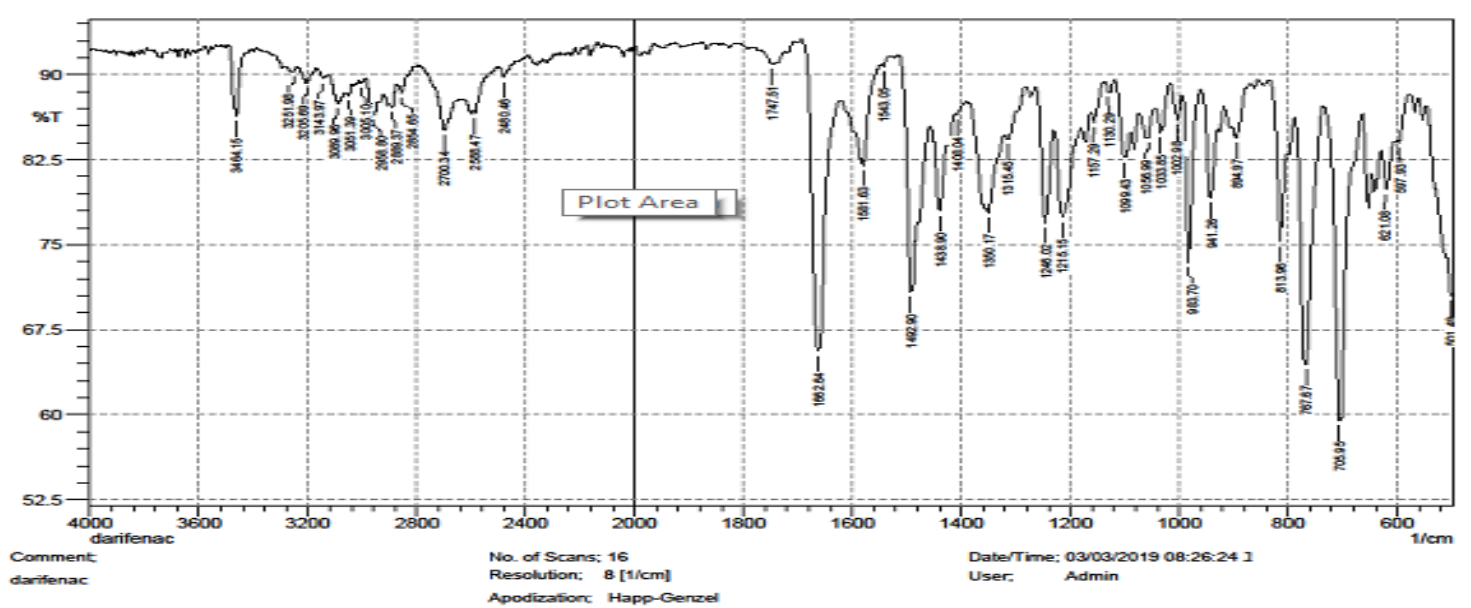

Figure 3. FTIR spectrum of darifenacin hydrobromide

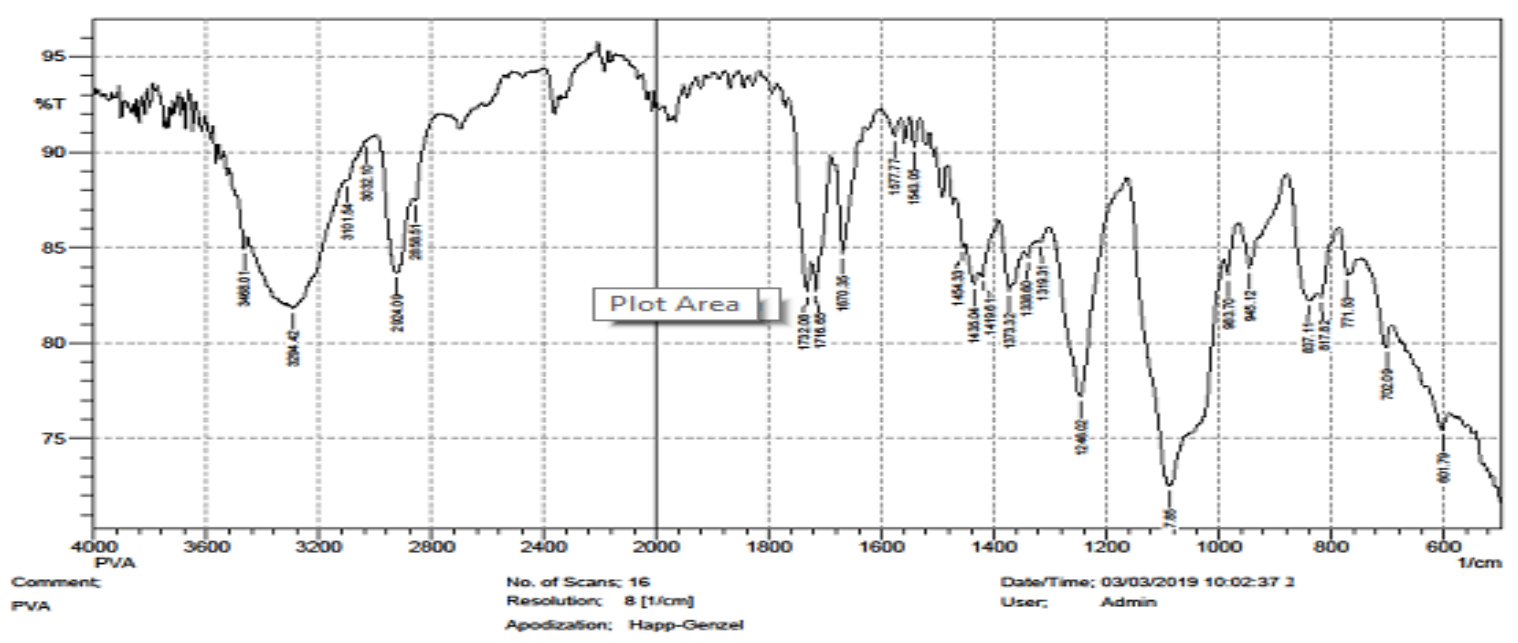

Figure 4.FTIR spectrum of PVA 
巴SHIMADzu

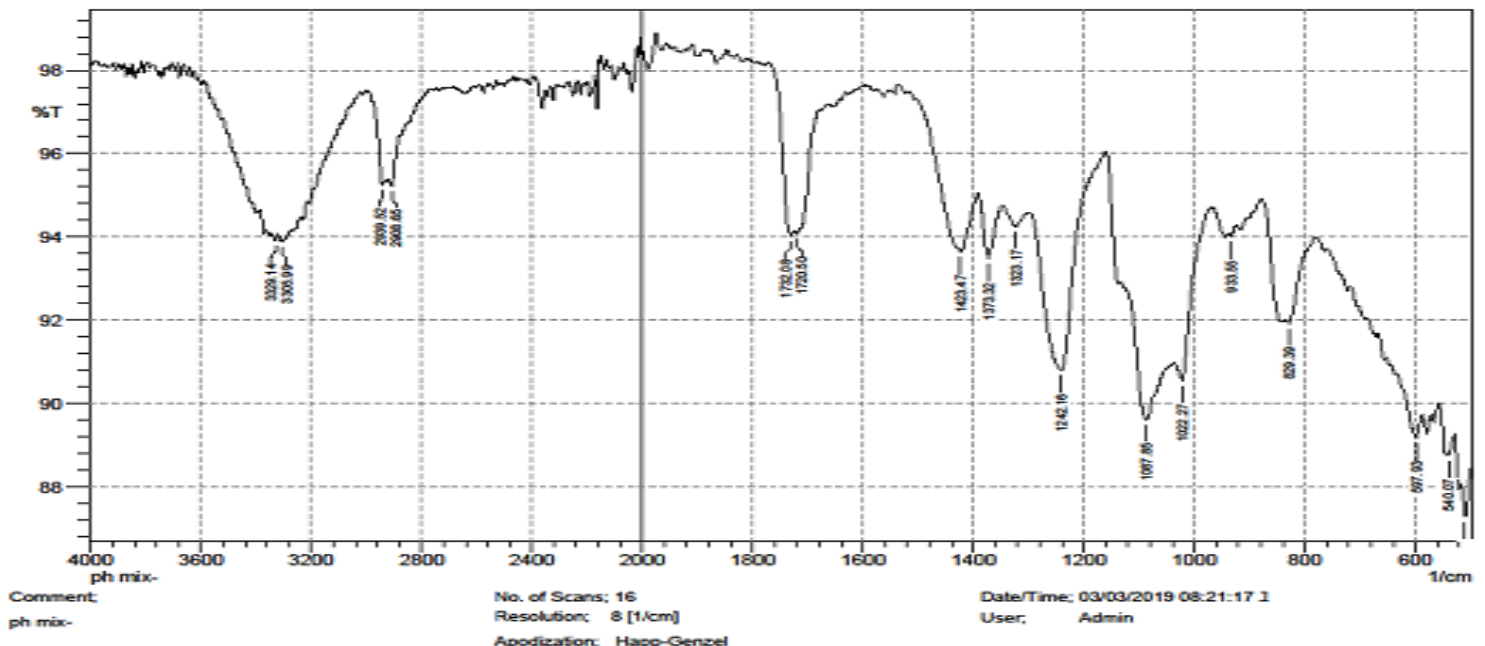

Figure 5. FTIR spectrum of physical mixture

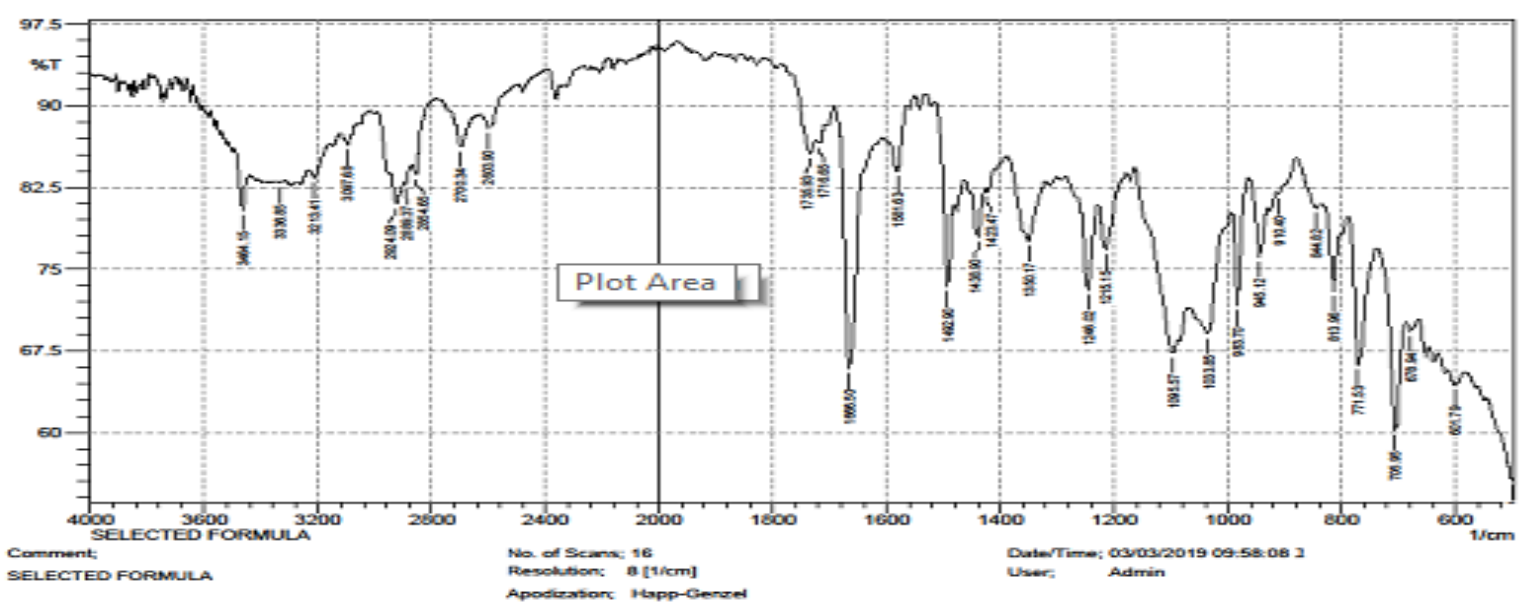

Figure 6. FTIR spectrum of (F9)

\section{Differential scanning calorimetry (DSC)}

DSC Technique has been performed to investigate thermal stability of DH and excipients. DSC of DH, PVA, (1:1) physical mixture of DH with PVA and F9 has been shown in figures 7, 8, 9 and 10 respectively.

A single peak confirming melting point of DH was detected at $235.8{ }^{\circ} \mathrm{C}$, indicating a crystal $\mathrm{DH}$ form. The peak of physical mixture revealed two peaks; one specific for DH and the other for PVA indicating that there was no interaction between them.

F9 showed a broad peak indicating complete disappearance of DH peak and proposing the dispersion of DH in amorphous form in the film and/or there was a complete homogeneous dissolution of DH in the polymer lattice.

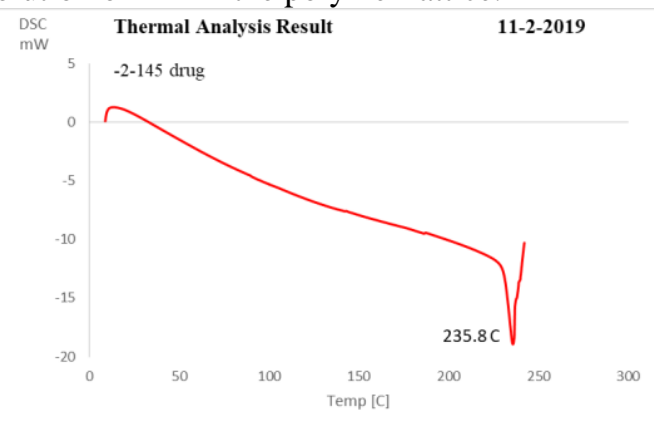

Figure 7. DSC of darifenacin hydrobromide 


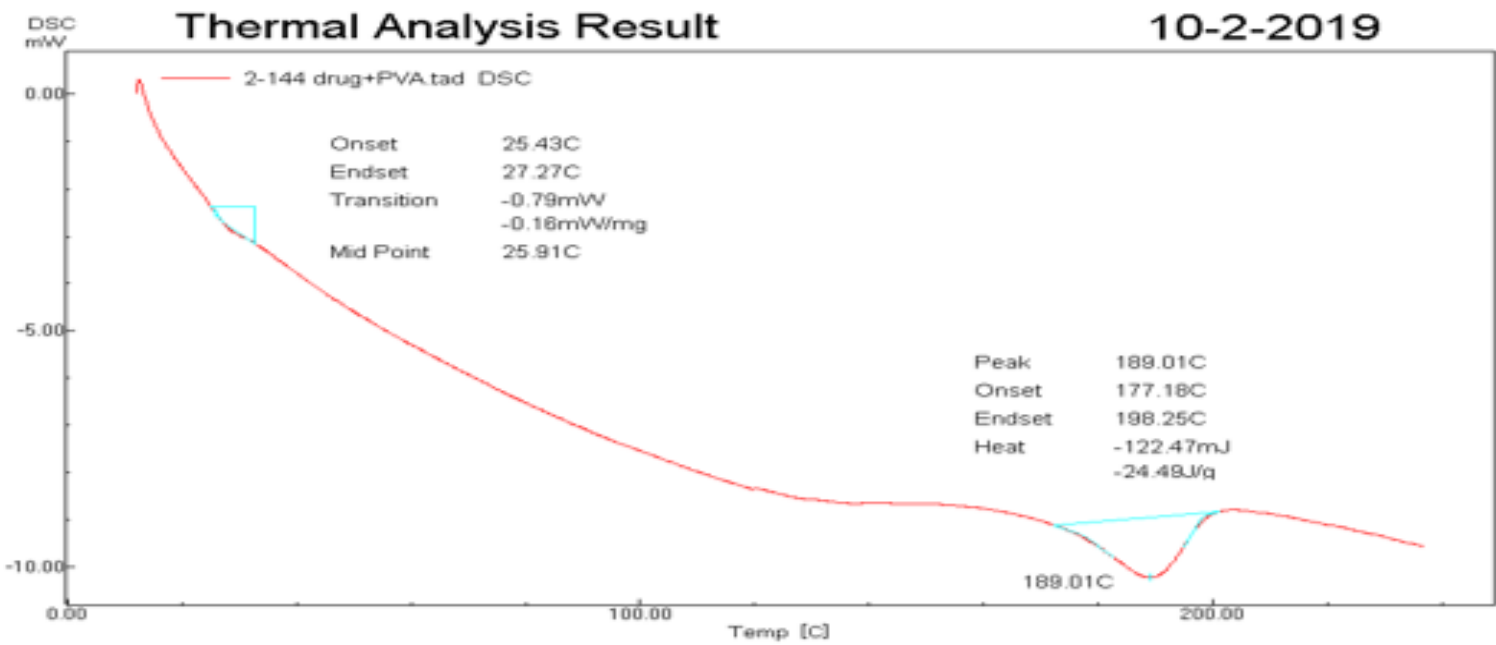

Figure 8. DSC of PVA

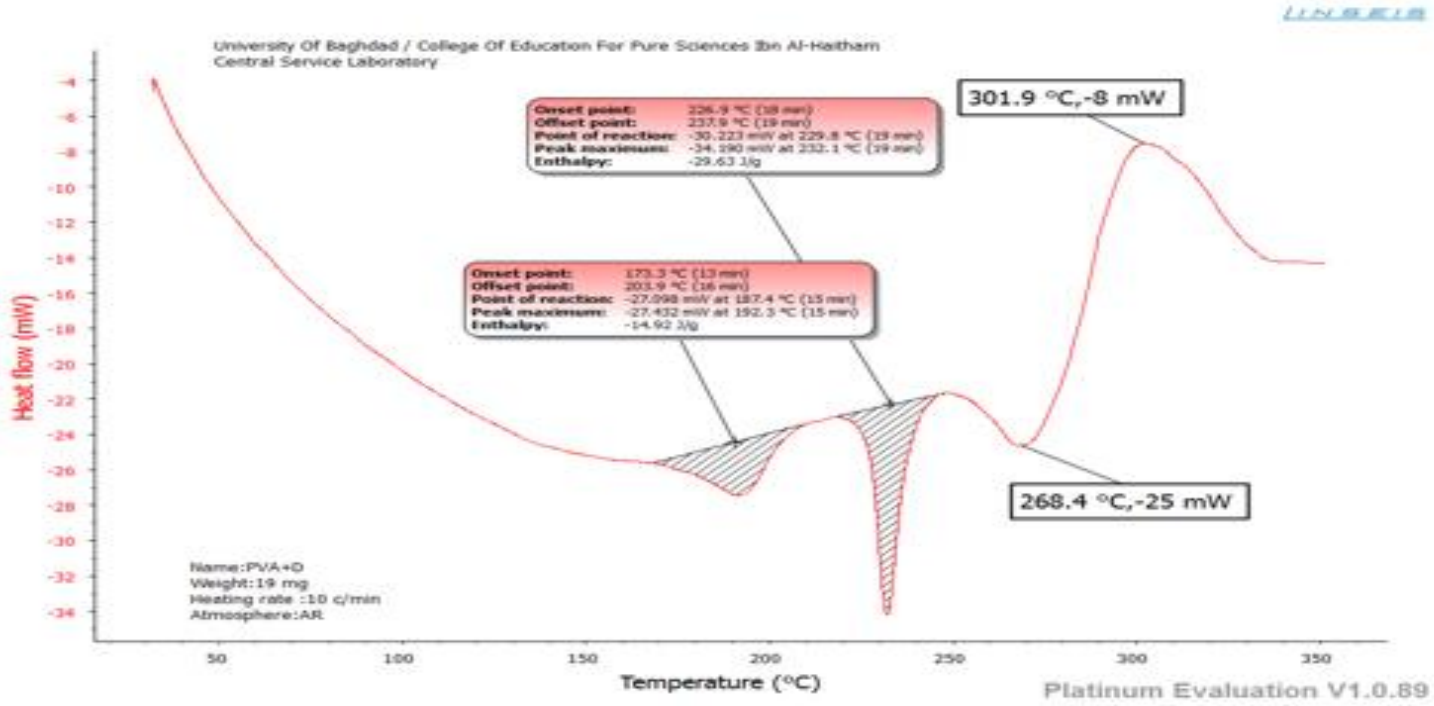

Figure 9. DSC of physical mixture

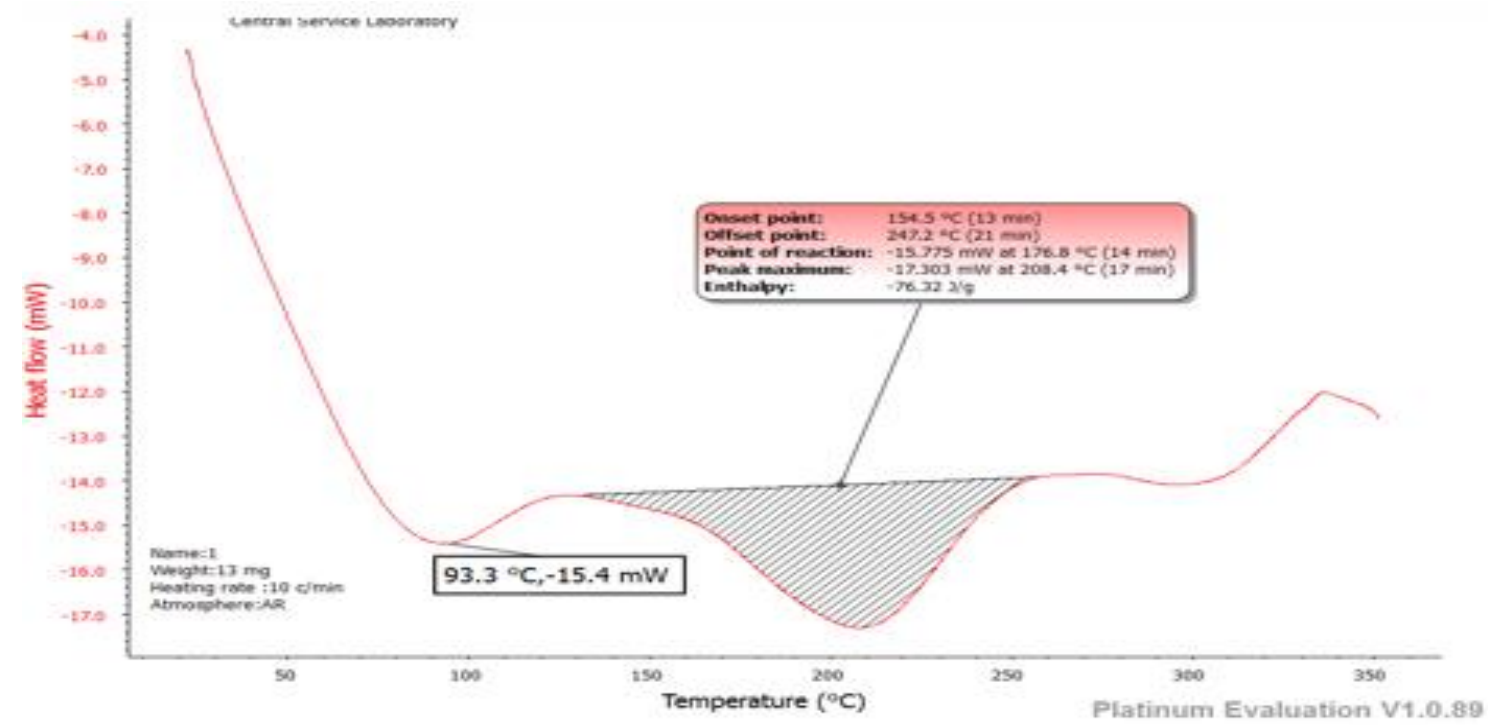

Figure 10. DSC of F9 


\section{$X$-Ray powder diffraction}

XRPD of DH, PVA, and F9 are presented in figures 11,12 and 13 .

XRPD of DH showing a typical crystalline pattern, that can be noticed by several sharp peaks (11.682, 18.426 and 20.426).
The XRPD of PVA has distinct peaks at 19.265, 19.863 and 21.408. However, XRPD of F9 represents an absence of all characteristic peaks of $\mathrm{DH}$ and PVA. These findings suggest that $\mathrm{DH}$ and PVA converted from crystalline to amorphous form.

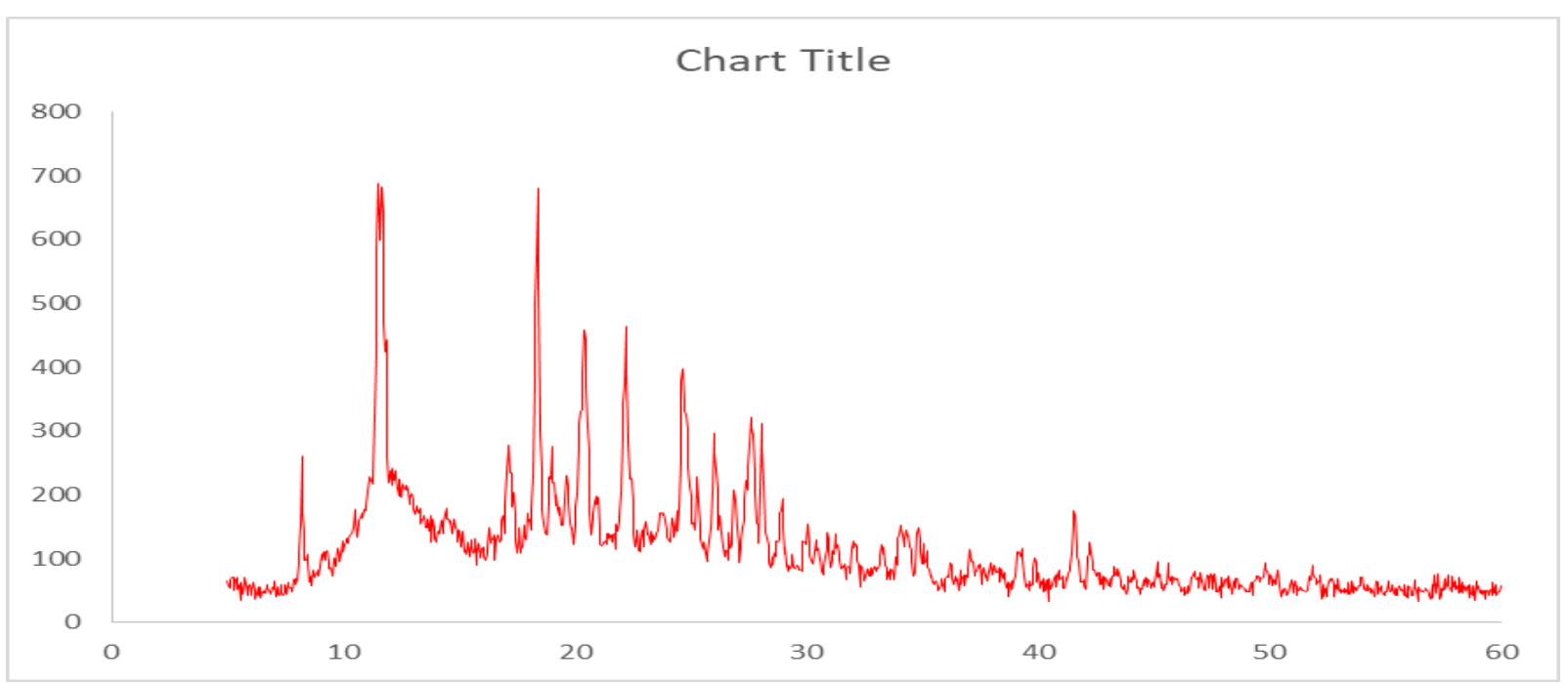

Figure 11. XRDP of pure darifenacin hydrobromide

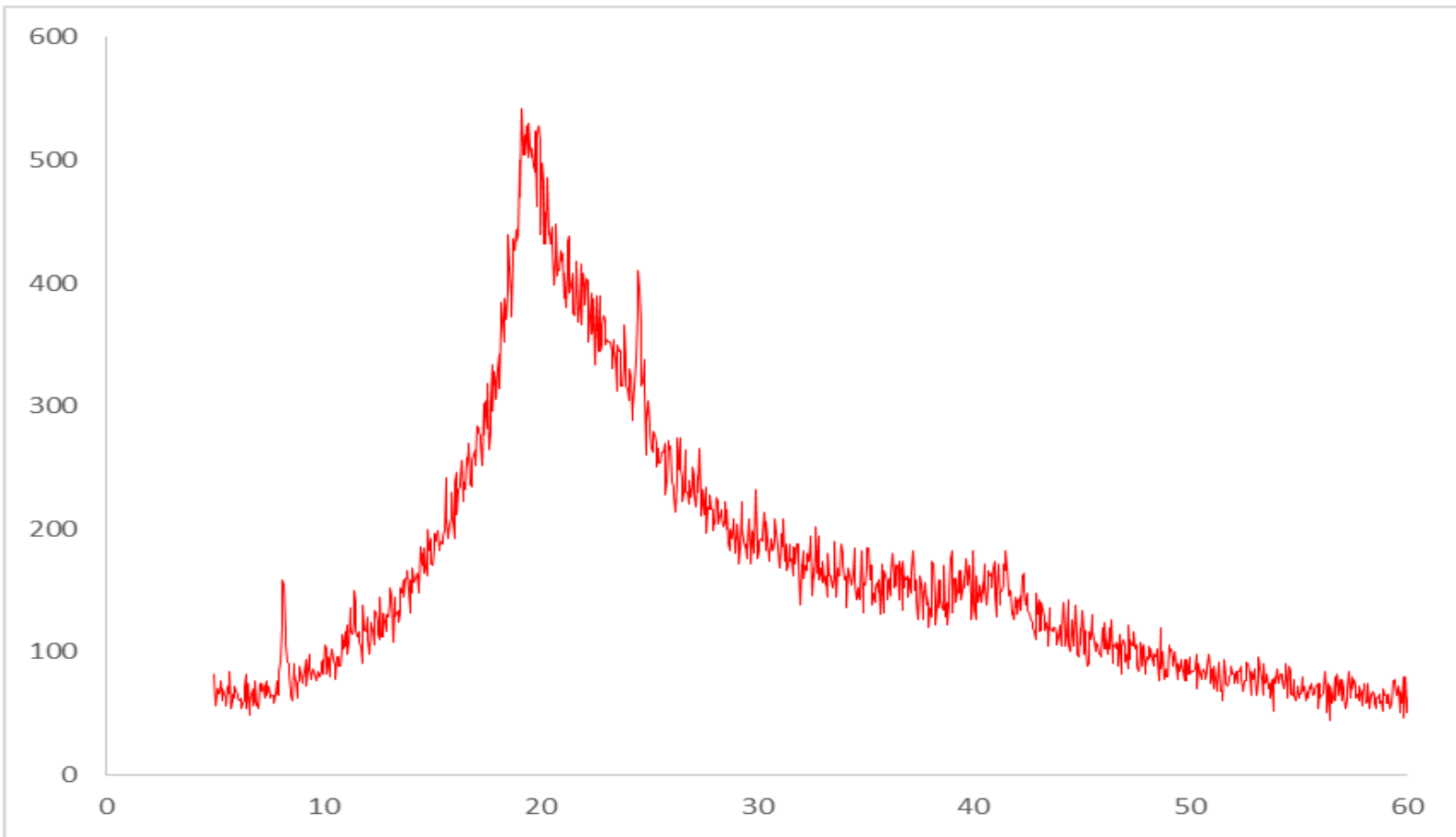

Figure 12. XRDP of PVA 


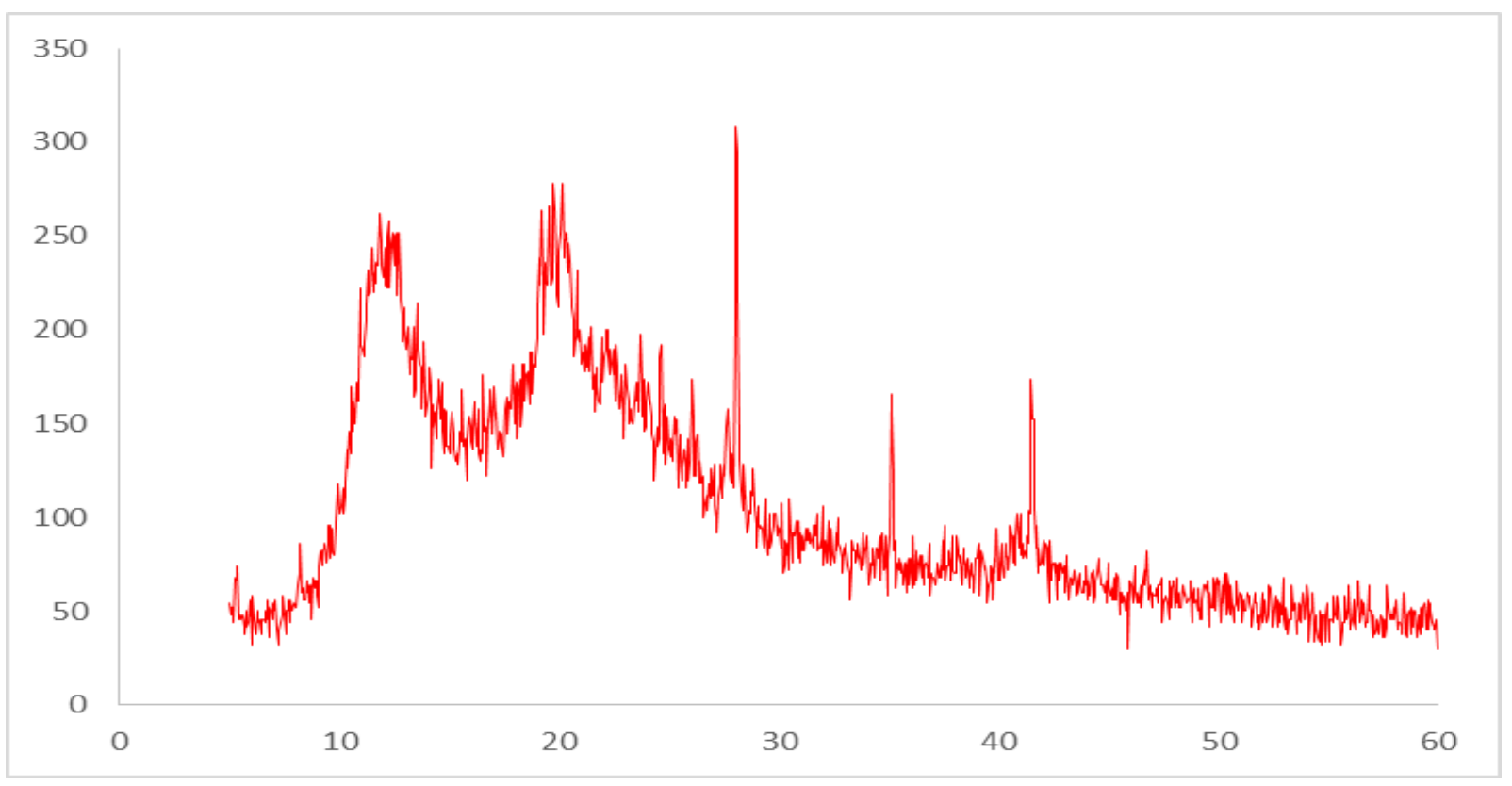

Figure 13. XRDP of F9

\section{Stability}

F9 stability was studied at three temperatures, $40{ }^{\circ} \mathrm{C}, 50{ }^{\circ} \mathrm{C}$ and $60{ }^{\circ} \mathrm{C}$ for three months. Figure 14 shows plot of logarithm percent remaining of $\mathrm{DH}$ versus time in weeks at different temperatures. The obtained profiles were linear indicating that $\mathrm{DH}$ degradation follows first order kinetics.

The degradation rate constant $(\mathrm{K})$ at every temperature was calculated from the slope of every line ${ }^{(26)}$

$$
\mathrm{K}=\text {-slopex } 2.303
$$

(6)

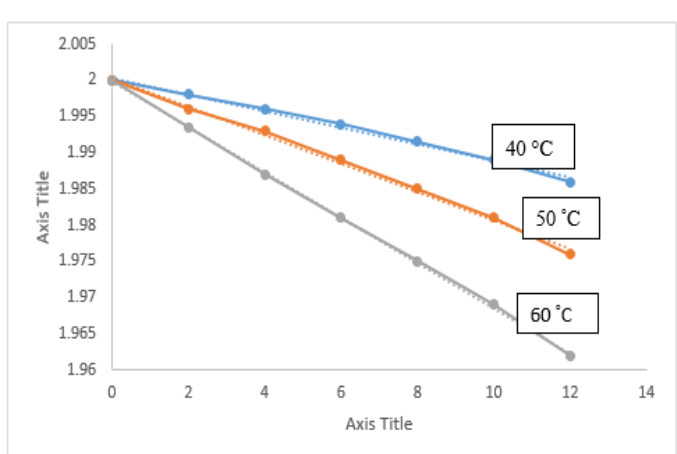

Figure 14. Degradation profile of darifenacin hydrobromide in $\mathrm{F9}$ at $40^{\circ} \mathrm{C}, 50^{\circ} \mathrm{C}$ and $60^{\circ} \mathrm{C}$

The values of $\mathrm{K}$ for each temperature are summarized in table 5 .
Table 5. Degradation rate constants $(K)$ of darifenacin hydrobromide in $\mathrm{F9}$ at $40{ }^{\circ} \mathrm{C}, 50^{\circ} \mathrm{C}$, and $60^{\circ} \mathrm{C}$

\begin{tabular}{||l|l||}
\hline \hline Temperature $\left({ }^{\circ} \mathbf{C}\right)$ & K(week \\
& \\
\hline 40 & $2.76 \times 10^{-3}$ \\
\hline 50 & $4.7 \times 10^{-3}$ \\
\hline 60 & $7.1 \times 10^{-3}$ \\
\hline
\end{tabular}

Expiration date was calculated from degradation rate constant at $25^{\circ} \mathrm{C}(\mathrm{K} 25)$ using Arrhenius plot equation (7) as shown in figure (15).

$\mathrm{T}_{90 \%}=0.105 / \mathrm{k} 25$ (7) At temperature $25^{0} \mathrm{C}$;

$\mathrm{K}=0.00126$ week $^{-1}\left(1.26 \times 10^{-3}\right.$ week $\left.^{-1}\right)$;

$\mathrm{T}_{90 \%}=83.4$ weeks $=1.6$ years.

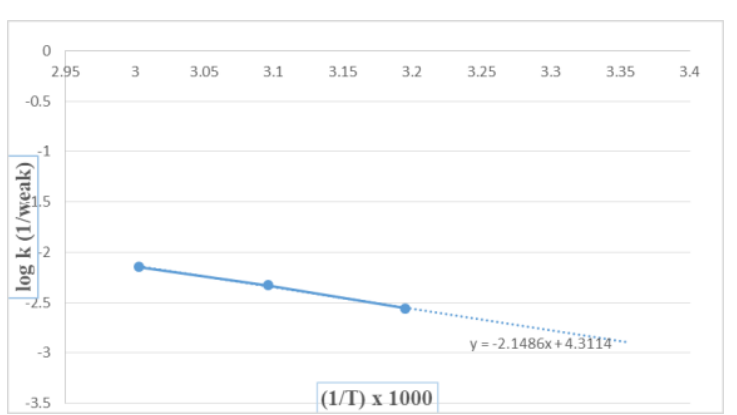

Figure 15. Arrhenius plot of darifenacin hydrobromide in $F 9$ for expiration date estimation

\section{Conclusion}

Based on obtained results; it was clear that the more concentrated superdisintegrant, the better disintegration rate and drug release, with superiority to indion 414 superdisintegrant and the FDBFs is a 
promising dosage form for releasing Darifenacin hydrobromide.

\section{References}

1. Patel VF, Liu F, Brown MB. Advances in oral transmucosal drug delivery. J Control Release. $2011 ; 153(2): 106-16$.

2. Siddiqui MDN, Garg G, Sharma PK. A short review on "a novel approach in oral fast dissolving drug delivery system and their patents". Adv Biol Res 2011;5(6):291-303.

3. Rajni B, Pravin P, Sushil K, Sandeep A. Orally dissolving strips: A new approach to oral drug delivery system. Int J Pharm Investig. 2013; 3(2):67-76.

4. Vaidya VS, Sandhyasree S, Shamili MS, Rukminidevi B, Nagavani $S$ et al. Mucoadhesive drug delivery system -an overview. International Journal of Investigation in Pharmaceutical Sciences. 2013;1(1):64-69.

5. Aulton, ME. Pharmaceutics the science of dosage form design. $2^{\text {nd }}$ ed. Churchill Livingstone, 2002;: 414-418.

6. Smith CM, Wallis RM. Characterization of $[3 \mathrm{H}]$-darifenacin as a novel radioligand for the study of muscarinic M3 receptors. J. Recept. Signal Transduct. Res. 1997; 17:177-85.

7. Felton LA, editor. Remington-essentials of pharmaceutics. Pharmaceutical Press; 2013.

8. Bayer G. Martindale: The complete drug reference Australian prescriber. 2015;38(2):59.

9. Noor AH, Khalil YI. Formulation and evaluation of felodipine orodispersible films. Pharmacie Globale. 2015;6(4):1.

10. Sri KV, Rohini P, Reddy GK. Montelukast sodium oral thin films: formulation and invitro evaluation. Asian J Pharm Clin Res. 2012; 5(4):266-70.

11. Tamer MA, Abd-AL Hammid SHN, Ahmed B. Formulation and In-vitro evaluation of bromocriptine mesylate as fast dissolving oral film. International Journal of Applied Pharmaceutics. 2018;10(1):7-20.

12. Jagdale SC, Mohanty $P$, Chabukswar AR, Kuchekar BS. Development of buccal patches for delivery of darifenacin from betacyclodextrin complexes. Journal of Basic and Applied pharmaceutical Sciences. 2014;35(1):29-39.

13. Vyas HD, Parmar G, Shah N, Chauhan S, Seth AK. Formulation and evaluation of fast dissolving film of methylcobalamin. Pharma Science monitor. 2015;6(4):50-68.
14. Jassim ZE, Mohammed MF, Sadeq ZA. Formulation and evaluation of fast dissolving film of lornoxicam. Asian J Pharm Clin Res. 2018;11(9): 217-23.

15. Londhe VY, Umalkar KB. Formulation development and evaluation of fast dissolving film of telmisartan. Indian $\mathbf{J}$ Pharm Sci. 2012;74(2):122-26.

16. Yuvraj GJ, Upendra CG, Pravin DC. Challenges in formulation development of fast dissolving oral films. IAJPR. 2013;3(8):6391407.

17. $\mathrm{Xu} \mathrm{H,} \mathrm{Li} \mathrm{J,} \mathrm{Fu} \mathrm{X.} \mathrm{Pharmacological} \mathrm{evaluation}$ of oral fast disintegrating films containing local anaesthetic agent lignocaine. Biomed Res. 2017;28(3):1135-141.

18. Shihora H, Panda S. Superdisintegrants, Utility in Dosage Forms: A Quick Review. JPSBR. 2011;1(3):148-53.

19. Gissinger D, Stamm A. A comparative evaluation of the properties of some tablet disintegrants. Drug Dev Ind Pharm. 1980;6(5):511-36.

20. Sharma D. Formulation development and evaluation of fast disintegrating tablets of salbutamol sulfate for respiratory disorders, ISRN Pharm. 2013; 2013(674507):1-8.

21. Haque SE, Sheela A. Development of polymer-bound fast-dissolving metformin buccal film with disintegrants. Int $\mathrm{J}$ Nanomedicine. 2015;10(1):199-205.

22. Chandira RM, Bhowmik D, Venkataeswarlu BS, Kumudhavalli MV, Jayakar B. Formulation and evaluation of taste masked fast dissolving tablets of ondansetron $\mathrm{Hcl}$. Journal of Pharmacy Research. 2008;1(2):200207.

23. Amin P, Prabhu N, Wadhwani A. Indion 414 as superdisintegrant in formulation of mouth dissolve tablets. Indian J. Pharm. Sci., 2006;68(1):117-19.

24. Jasim IK. Formulation and evaluation of mouth dissolving films of captopril. Master thesis. University of Baghdad. College of Pharmacy. 2006: 59.

25. Arora L, Chakraborty T. A review on new generation orodispersible films and its novel approaches. IAJPA. 2017 Jan;7(1):7451-70.

26. Martin AN, Sinko PJ, Singh Y. Chemical kinetics and stability. In: Martin's physical pharmacy and pharmaceutical sciences. 6th ed. Baltimore, MD: Lippincott Williams \& Wilkins; 2011. 318-54 p.

Baghdad Iraqi Journal Pharmaceutical Sciences by bijps is licensed under a Creative Commons Attribution 4.0 International License. Copyrights@ 2015 College of Pharmacy - University of Baghdad. 